\title{
Research on Establishment Motivation of the Supply Chain of Agricultural Fruits and Vegetables and Their Circulation Mode \\ *Wangweina ${ }^{1, a}$

\author{
${ }^{1}$ University for Science \& Technology Zhengzhou, Zhengzhou 450052,China \\ awangweina415@sohu.com
}

\begin{abstract}
Keywords: Supply chain of agricultural products. Farmer-supermarket docking. Circulation mode. Joint distribution
\end{abstract}

\begin{abstract}
Traditional sale of agricultural products needs to experience one or several interminable supply chains of "farmers $\rightarrow$ farmland market $\rightarrow$ regional wholesale $\rightarrow$ farmer's market $\rightarrow$ retailers", which leads to great rise of the cost of agricultural products and the increase of commodity consumption. According to statistics, the loss ratio in the links of picking, transportation and storage of fruits and vegetables in our country is more than 3 times of that in advanced countries. This is a large loss for supermarkets and farmers. Therefore, it is a problem which is worthwhile to be emphasized and researched to unblock and facilitate the downstream retail channels, achieve the docking between production and circulation and guarantee the quality safety of agricultural products. Through the research on establishment motivation of the supply chain of agricultural fruits and vegetables, this paper puts forward "farmer-supermarket docking" supply chain management mode which can adapt to the demand of market.
\end{abstract}

\section{Supply chain of agricultural fruits and vegetables and their establishment motivation}

\subsection{Supply chain of agricultural fruits and vegetables}

The supply chain of agricultural fruits and vegetables relies on advanced computer network technology, centers on core enterprises to effectively transport, store, process, loading and unloading, carry, pack and circularly process, and distribute agricultural fruits and vegetables, utilizes information system to connect producers, wholesalers, retailers and the terminal users and form a complete network structure, achieves unblocked circulation channel of agricultural fruits and vegetables, decreases first-class product consumption and logistics cost and promotes the level of logistics service. The establishment of agricultural fruits and vegetables supply chain needs the mutual support and cooperation among the node enterprises on the supply chain. The traditional profit maximization of single target or single enterprise shall be changed. Every node enterprise must realize that it is one of the members of the agricultural fruits and vegetables supply chain. Each member must promote integration operation and achieve the maximization of entire benefits for achieving the common target.

\subsection{The establishment motivation of agricultural fruits and vegetables supply chain}

Facing the current development situation of the logistics of agricultural fruits and vegetables and considering the features of the logistics of agricultural fruits and vegetables, it is an important method of promoting the circulation efficiency of agricultural fruits and vegetables to establish agricultural fruits and vegetables supply chain based on "farmer-supermarket docking". From the source of production to the dining table of consumers, the value and edibleness of agricultural fruits and vegetables shall be sufficiently achieved; in addition, the benefits of consumers shall be guaranteed and they can be guaranteed to buy safe and fresh agricultural fruits and vegetables. Through establishing agricultural fruits and vegetables supply chain, strategic cooperative partnership relationship among the producers, wholesalers, circulation processing and distribution center and retailers of agricultural products can be established; the intermediate links of agricultural products can 
be decreased; the feedback information of market can be rapidly responded; valid mechanism of information share and shared risk responsibility can be established. The main motivations of establishing agricultural fruits and vegetables supply chain are in the following:

\subsubsection{To achieve large-scale and intensive operation}

At present, logistics of agricultural fruits and vegetables is a process of dispersal $\rightarrow$ assembly $\rightarrow$ distribution. At the source of supply, the production scale of farmers is small and the layout is disperse. In this case, agricultural fruits and vegetables need to be assembled firstly. After they are assembled, they will be transported to processing enterprises and wholesale markets and be processed or further transported. Through trading markets, supermarkets and other retail channels, agricultural fruits and vegetables can finally reach consumers. In the whole circulation process of agricultural fruits and vegetables, logistics is difficult to be controlled and management is complex and chaotic。The establishment of agricultural fruits and vegetables supply chain shall start from supply source. The disperse farmer families are managed intensively; agricultural products can be purchased intensively; the fluctuation of product supply can be decreased; farmers' ability of resisting market risk can be promoted; the benefits of farmers can be effectively protected. As for the downstream node enterprises on the supply chain, through establishing agricultural fruits and vegetables supply chain, retail channels can be integrated; integration management can be achieved; the circulation of agricultural fruits and vegetables can be accelerated.

\subsubsection{To decrease the fluctuation of demand \& supply information and achieve information symmetry}

The logistics of agricultural fruits and vegetables is a process of dispersal $\rightarrow$ assembly $\rightarrow$ distribution. The disperse layout of farmers and chaotic circulation channels lead to severe asymmetry and distortion of demand \& supply information. The circulation of agricultural fruits and vegetables is severely disordered. There is no uniform channel to collect, arrange and issue demand \& supply information of agricultural fruits and vegetables. In this case, the value of the products of farmers cannot be achieved and the benefits of farmers will be damaged. The information of retail channel cannot be got properly and the purchase desire of consumers cannot be satisfied. In this case, the business opportunity at retail terminal will be lost. Through establishing agricultural fruits and vegetables supply chain, considering the timeliness of agricultural production and the permanence of consumption demand and regulating information collection channels, information share among the nodes of the supply chain can be achieved; demand \& supply information can be accurately captured; the benefits of farmers can be effectively maintained; the value of products can be increased in circulation process and the demand of consumers can be satisfied.

\subsubsection{To decrease links of circulation}

In the circulation channel of agricultural fruits and vegetables, wholesale market is the core. The main circulation process is "producers $\rightarrow$ wholesale markets in consuming place $\rightarrow$ retailers $\rightarrow$ consumers". In the process of wholesale, the products can enter circulation channel after first-level wholesale market, second-level wholesale market and even third-level wholesale market assemble goods and distribute goods. The defect of circulation channel with the core of wholesale market is in the link of circulation. Firstly, there are many participants. From purchase, wholesale in producing area, wholesale in collecting and distributing place and wholesale in sale place to the final retail, many transaction subjects participate in the process of circulation. The main trading mode is spot trading. Search cost of trade information is high; the time spent is much; transaction procedures can be blocked. Transaction links will be increased. Secondly, the process of transportation is complex. From place of production to place of sale, products can be assembled and distributed for several times. Entrustment transportation is the main mode of transportation. In the aspects of arranging transportation route and selecting transportation vehicles, scientific planning and reasonable operation lack, which adds to the uncertainty of transportation link. Through establishing agricultural fruits and vegetables supply chain, alliance of strategic partners can be established; goods can be 
offered stably depending on the stable cooperative partner relationship; scale economy of the flow of agricultural fruits and vegetables can be achieved; transaction cost can be decreased. The information exchange among the node enterprises on the supply chain of agricultural fruits and vegetables shall be strengthened; the transaction procedures among node enterprises shall be optimized; the management on logistics resources (transportation, storage etc.) of node enterprises shall be optimized; resource integration shall be achieved; the efficiency of logistics (transportation, loading and unloading, distribution) can be promoted; circulation links can be decreased.

\subsubsection{To promote the level of logistics technology}

At present, agricultural fruits and vegetables are mainly transported in normal temperature. In addition, they are usually stored in simply equipped warehouse. The facility of cold storage and retaining freshness is behindhand. The level of automation of logistics operation is not high. In this case, a large amount of agricultural fruits and vegetables decay in the processes of transportation, storage and carry. According to statistics, the loss rate of the agricultural fruits and vegetables in our country is $25 \%-40 \%$ in the processes of picking, transportation and storage (China Logistics Statistics Yearbook). In the process of wholesale, hardware facilities and equipments are behindhand. Outdoors transaction is the main mode. The ancillary facilities of distribution processing, storage, retaining freshness, distribution etc. are not complete. There are few wholesale markets which are equipped with information facilities of information management system, information collection and issue system etc. At the terminal of retail, traditional transaction mode still plays a leading role. On-the-spot transaction is the main transaction mode in trading markets. The sanitary condition of freshness preservation box is poor. In the aspect of logistic distribution of supermarket, the usage rate of bar code technology, automatic identification system, automatic sorting system, automatic storage system and automatic tracing system for goods is low. This badly influences the efficiency and quality of the distribution of agricultural fruits and vegetables in supermarkets. In addition, the intensive purchase amount of agricultural fruits and vegetables is small in the retail channel of supermarket; Through establishing the supply chain of agricultural fruits and vegetables, the node enterprises shall utilize their own competitive advantages, increase investments, improve logistics facilities and equipments, coordinate the use and management of facilities and equipments among node enterprises, and promote the utilization and share of advanced logistic technology in the node enterprises of the supply chain.

\section{Research on the management mode of agricultural fruits and vegetables supply chain based on "farmer-supermarket docking"}

2.1 The management mode of "farmer-supermarket docking" supply chain based on common distribution

This mode emphasizes the characteristic of reciprocity and mutual benefit, intensifies the management on fresh food and guarantees the safety of the fruits and vegetables in supermarkets. From purchase and processing to sale of fresh food, bidirectional management is implemented. Large-scale logistic center is responsible for the logistic activities and management in the upstream of supply chain including transaction of fruits and vegetables, quality safety detection, scientific and technological research and development of agricultural products, storage and logistic distribution. As for downstream, chain supermarkets are responsible for selling the upstream products to downstream consumers. As the two main node enterprises of the supply chain, logistics center and chain supermarket coordinate and promote each other. They jointly offer logistic distribution service and guarantee the optimal quality of fresh food. At the same time, they establish stable sale channel for agricultural products. 
2.2 The management mode of "farmer-supermarket docking" supply chain based on self-support logistics of supermarket

This management mode of supply chain optimizes and improves the typical "farmer-supermarket docking" mode mentioned in the second chapter. In this mode, supermarket utilizes its own scale and conditions, sets up special "direct-purchase" group, utilizes its own logistic department and selects the cooperative which has certain scale and has the ability to produce characteristic agricultural products with high quality, cooperates with them and offers the support of scientific technology or funds when it is necessary. In this management mode of supply chain, as the core enterprise on the chain, the logistics center of supermarket is responsible for overall planning with full authority, purchases products in order orientation and organizes logistic distribution. On the supply chain, chain supermarkets neighbor consumption market and have the ability to accurately forecast the demand of market. In this case, the demand of market can drive production and operation; the fixed goal can be achieved at the first time.

2.3 The logistics mode of "farmer-supermarket docking" supply chain based on the logistics of the third party

In this mode, supermarket entrusts third-party logistics company to be responsible for the activities on agricultural products supply chain with full authority. Farmers are organized to plant fruits and vegetables and logistics company supervises and guides them. In addition, third-party detection organization is entrusted to detect the quality of agricultural products. At last, in the organization and coordination of third-party logistics company, agricultural products can be delivered to supermarkets at the first time to meet the demand of consumers. As is shown in figure 4-11, this mode is suitable for small-sized supermarkets which cannot bear the pressure of large-scale investment and suitable for the purchase of some seasonal agricultural fruits and vegetables. Supermarkets can use outsourcing mode to outsource transportation and storage to third-party logistics company. In this way, supermarket can focus more on the promotion of its core competitiveness.

\section{Conclusion}

As a new mode of selling agricultural products for farmers, "farmer-supermarket docking" inevitably faces kinds of problems and challenges at the beginning like all of new things. It is impossible for farmers to master the operation idea of modern enterprises in short time. Their production technology and equipments are impossible to immediately meet the requirements of modern supermarkets. In fact, the demands of consumers transmitted from supermarket are the requirements on "modern agriculture". Through "farmer-supermarket docking", some problems can be found and the methods and approaches of solving the problems can also be found. Transaction costs can be decreased; the safety of agricultural products can be promoted; income of farmers can increase. In addition, it will accelerate the modernization of the agriculture and farmers of our country. This is the important significance of "farmer-supermarket docking".

\section{References}

[1] Chen Ke, Le Bijun. Research on the supply chain management mode based on farmer-supermarket docking [J]. Logistics engineering and management, 2011, 33(10): 87-90.

[2] Zhang Shuang, Xu Zheng. Discussion on new agricultural product circulation system based on farmer-supermarket docking mode [J]. Anhui Agricultural Science, 2010, 38 (22): 12212-12214.

[3] Chen Huicai. Innovative practice on the supply mode of fresh fruits and vegetables in Weifang City based on "farmer-supermarket docking" [J]. Anhui Agricultural Science, 2011 (34)

[4] Li Huijuan, Zhao Tingting, Zhang Mao. Existing problems in agricultural products supply chain based on "farmer-supermarket docking" and countermeasures [J]. Modern agricultural science and technology, 2011(18): 394-396 
[5] Wang Yongsheng. Research on the logistics operation mode in "farmer-supermarket docking" [J]. Logistics science and technology, 2010(11):93-97 